\title{
Model Permainan Colourfull Ball Target dalam Pembelajaran Permainan Bola Kecil Bagi Siswa Tunarungu
}

\author{
Aris Mulyono $^{1^{*}}$, Harry Pramono ${ }^{2}$, Siti Purwanti ${ }^{3}$ \\ 1,2,3 Gedung F1 Lantai 2 FIK Unnes Kampus Sekaran, Gunungpati, Semarang, 50229
}

*Corresponding author: arism.atmadja@yahoo.co.id

\section{ARTICLE INFO}

Article history:

Received 27 July 16

Received in revised form 10 August 16

Accepted 07 September 16

\section{Keywords:}

Development; Small Ball Game;

Colourful Ball Target Game; Deaf

\begin{abstract}
A B S T R A C T
The aim of this research was to find out the learning result of the education of physical, health, and recreation through colorful ball target game in the learning of small ball game for the deaf students of Special Primary School in Kudus Regency. The research method was developmental research which referred to developmental model of Borg \& Gall. The research result was validation from the expert which was obtained from initial product evaluation data. They were adaptive physical education expert $72.00 \%$ (good) and the education of physical, health, and recreation expert $74.66 \%$ (good). Small group test was adaptive physical education expert $81.33 \%$ (good) and the education of physical, health, and recreation expert $85.33 \%$ (good). Meanwhile, for the field try-out $89.75 \%$ (good). Based onth research result above, it can be concluded that this Colorful Ball Target game can be applied to the deaf students of Special Primary School in Kudus Regency. This game model is suggested for PJOK teachers of Special Primary School in Kudus Regency to be the alternative in delivering the small ball game material. It is expected that the learning will be more interesting and safer for students.
\end{abstract}

\section{Pendahuluan}

Pengajaran penjas adaptif yang diberikan disesuaikan dengan jenis dan karakteristik kelainan siswa. Hal ini dimaksudkan untuk memberikan kesempatan kepada siswa yang mempunyai kelainan dapat berpartisipasi aktif dengan aman, dan memperoleh kepuasan. Serta tujuan dari pendidikan jasmani adaptif itu sendiri adalah membantu siswa yang mempunyai kebutuhan khusus serta untuk melindungi dirinya sendiri dari kondisi apapun dan memberikan kesempatan pada siswa untuk mempelajari dan berpartisipasi dalam aktivitas olahraga dan jasmani salah satunya anak tunarungu.

Karakteristik anak tunarungu yang memiliki kendala dalam berkomunikasi dan tidak mampu memahami apa yang lawan bicarakan. Untuk memperlancar komunikasi dengan cara memberikan isyarat-isyarat melalui tangan. Dilihat dari segi fisiknya, anak tunarungu memiliki fisik yang sama dengan anak normal pada umumnya, yang menjadi perbedaan dalam proses pembelajaran adalah bagaimana cara siswa tunarungu menerima informasi ataupun materi saat pembelajaran yang diberikan oleh guru. Serta cara penyampaiannya dalam proses pembelajaran.

Beberapa faktor yang mempengaruhi kondisi pelaksanaan penjas dan olahraga pada siswa berkebutuhan khusus di Indonesia antar lain, profesionalitas dan kualitas guru penjas, kondisi lingkungan di sekolah luar biasa dan kualitas siswa sekolah berkebutuhan khusus. Berkaitan dengan kondisi lingkungan sekolah dan minimnya sarana dan perasarana yang umumnya dialami SLB akan berpengaruh terhadap derajat kebugaran jasmani, khususnya daya tahan jantung dan paru paru. Diketahui keterbatasan sarana dan prasarana yang dimiliki SLB serta kondisi lingkungan yang tidak kondusif menyebabkan keterbatasan gerak bagi siswa. Selain itu komponen fisik lain juga terpengaruh seperti, kekuatan otot, kelentukan, daya tahan otot, waktu reaksi dan keseimbangan juga sangat rendah. Rendahnya kebugaran atau kualitas fisik siswa penyandang cacat tersebut akibat kurangnya aktivitas gerak fisik karena sikap over protective dari keluarga, termasuk sering merasa kasihan, tidak acuh, lingkungan kurang mendukung, membatasi ruang lingkup gerak dalam rangka mengawasi keamanan. Untuk meningkatkan kesehatan dan kebugaran jasmani parasiswa, kualitas proses pembelajaran penjas adaptif di SLB perlu ditingkatkan melalui peningkatan kualifikasi, kualitas dan kompetensi guru penjas adaptif, serta perlu ditunjang peningkatan saran dan prasarana. Salah satunya di Kabupaten Kudus, terdapat 4 (empat) Sekolah Dasar Luar Biasa pada tahun 2016 yaitu 3 (tiga) Sekolah Dasar Luar Biasa yang berstatus Negeri dan 1 (satu) Sekolah Dasar Luar Biasa yang berstatus Swasta. Dari 3 (tiga) Sekolah Dasar Luar Biasa yang berstatus Negeri antara lain SLB N Purwosari, SLB N Kaliwungu dan SLB N Cendono, sedangkan Sekolah Dasar Luar Biasa yang Berstatus swasta adalah SLB Sunan Muria.

Menyadari pentingnya aktivitas gerak untuk anak tunarungu peneliti melakukan observasi awal pelaksanan proses pembelajaran penjas di SDLB dan melalui wawancara dengan guru penjas dan guru kelas pada hari Kamis, tanggal 11 februari 2016 hal ini dilakukan untuk mengetahui proses pembelajaran penjas pada anak tunarungu dilapangan. Berdasarkan hasil observasi/pengamatan dan wawancara dalam pelaksanaan pembelajaran penjas adaptif di 3 sekolah yaitu diketahui bahwa pelaksanaan proses pembelajaran penjas di SDLB $\mathrm{N}$ cendono sekolah sudah mempunyai kurikulum khususuntuk anak Tunarungu namun dalam proses pembelajaran di lapangan guru belum terlaksana dengan baik yaitu materi yang diberikan masih materi keinginan siswa, 
sedangkan di SDLB N Purwosari Kudus dlam proses pelaksanaan pembelajaran anak tunarungu melaksanakan pembelajaran penjas bersamaan dengan anak tunagrahita seharusnya setiap ketunaan itu berbeda dalam pelaksanaan pembelajaran penjas, untuk SDLB $\mathrm{N}$ Kaliwungu Kudus sekolah hanya melaksanakan pembelajaran penjas satu kali dalam seminggu untuk semua ketunaan, saranan prasarana yang digunakan untuk ketiga sekolah masih kurang memadahi, masih banyak anak yang belum fokus ataupun berkonsentrasi terhadap instruksi yang diberikan oleh guru.

\section{Metode Penelitian}

Metode yang digunakan dalam penelitian pengembangan merupakan penelitian yang bertujuan menghasilkan produk berupa pengembangan model permainan Colourfull Ball target dalam pembelajaran Permainan bola kecil bagi siswa Tunarungu SDLB N. Menurut borg dan gall dalam sugiyono (2010:9), peneliti dan pengembangan atau yang lebih dikenal dengan istilah Research and Development $(R \& D)$ merupakan metode penelitian yang digunakan untuk mengembangkan atau memvalidasi produk-produk yang digunakan dalam pendidika dan pembelajaran.

\section{Subjek penelitian}

Subjek uji coba dalam penelitian adlah sebagai berikut:

1) Evaluasi ahli yang terdiri dari satu ahli penjas adaptif dati dosen PJKR UNNES yaitu Bapak Drs. Cahyo Yuwono.M.Pd, dan tiga ahli penjasorkes dari guru penjasorkes SDLB N di Kabupaten Kudus yaitu Bapak Sutarjo,S.Pd, Bapak Fikri Yosi Irawan,S.Pd, dan Ibu Pujiyarti,S.Pd.

2) Uji kelompok kecil terdiri dari 10 siswa SDLB N Cendono Kabupaten Kudus.

3) Uji coba lapangan terdiri dari 10 siswa SDLB Npurwosari dan 10 siswa SDLB N Kaliwungu Kabupaten Kudus.

\section{Prosedur Pengembangan}

Prosedur pengembangan model permainan Colourfull Ball Target dalam pembelajaran permainan bola kecil bagi siswa tunarungu SDLB $\mathrm{N}$ di Kabupaten Kudus dilakukan melalui tahapan:

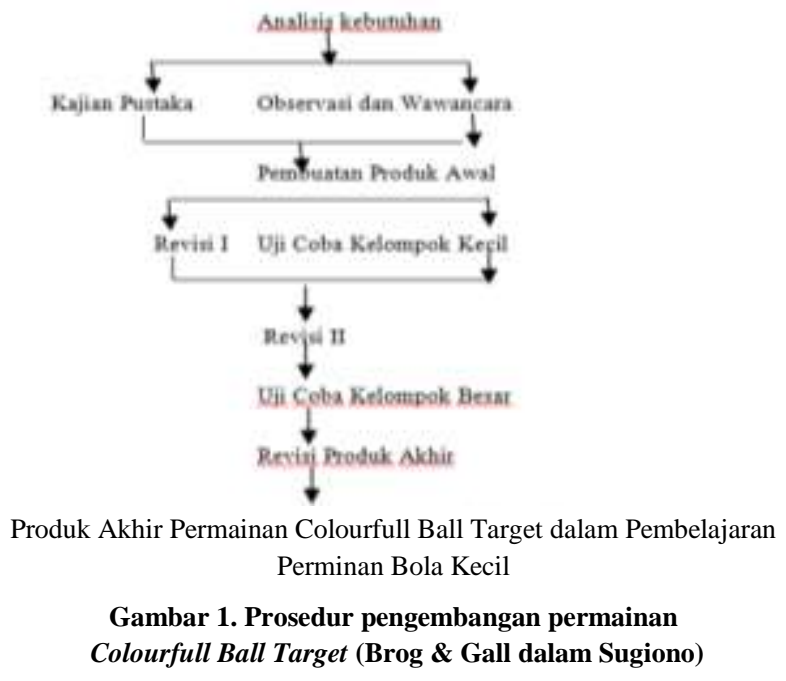

\section{Analisis Kebutuhan}

Analisis kebutuhan merupakan langkah awal dalam melakukan penelitian ini. Langkah ini bertujuan untuk apakah perminan Colourfull Ball Target ini efektif dalampembelajaran permainan bola kecil bagi siswa tunarungu SDLB N di Kabupaten Kudus. Pada tahapan ini peneliti melakukan observasi di SDLB $\mathrm{N}$ di Kabupaten Kudus tentang pelaksanaan pembelajaran permainan bola kecil dan melakukan wawancara dengan guru penjasorkes yang bersangkutan.

\section{Pembuatan Produk Awal}

Dalam pembuatan prosuk yang akan dikembangkan, peneliti membuat produk berdasarkan kajian teori yang kemudian dievaluasi oleh satu ahli penjas adaptif dan satu ahli penjasorkes. Subjek dalam penelitian ini adalah siswa tunarungu SDLB N Cendono Kabupaten Kudus yang berjumlah 10 (sepuluh) siswa.

\section{Uji Coba Kelompok Kecil}

Tahap uji coba kelompok kecil melibatkan 10 (sepuluh) siswa SDLB Negeri Cendono untuk melakukan eksperimen atau percobaan kelompok kecil yang dKabupaten Kudus. Selanjutnya hasil uji coba kelompok kecil dilakukan evaluasi dan penyempurnaan seperlunya.

\section{Uji Coba Kelompok Besar}

Hasil analisis kelompok kecil serta revisi pertama, selanjutnya dilakukan uji coba lapangan/ skala besar. Uji coba skala besar terdiri dari 20 siswa tunarungu yaitu 10 siswa dari SDLB N Purwosari dan 10 siswa tunarungu dari SDLB N Kaliwungu Kabupaten Kudus. Stelah melakukan permainan tersebut siswa mengisi kuesioner tentang permainan Colourfull Ball Target yang telah dilakukan.

\section{Jenis Data}

Data yang diperoleh adalah data kualitatif dan kuantitatif yang dihasilkan dari wawancara guru Pendidikan Jasmani Olahraga Dan Kesehatan dan tes lembar kuesioner pada siswa. Data yang diperoleh juga dari kritik dan saran dari ahli permainan dan ahli pembelajaran sebagai masukan untuk bahan revisi produk.

\section{Instrumen Pengumpulan Data}

Teknik pengumpulan data yang digunakan dalam penelitian adalah lembar evaluasi, lembar kuesioner, lembar wawancara dan lembar observasi. Instrumen yang digunakan dalam pengumpulan data adalah berupa lembar evaluasi. Lembar evaluasi digunakan untuk mengumpulkan data dari ahli penjasorkes dan ahli penjas adaptif yang berhubungan dengan produk yang dikembangkan.

\section{Teknik Analisisi Data}

Teknik analisis data yang digunakan dalam penelitian pengembangan ini adalah menggunakan teknik analisis deskriptif berbentuk persentase. Sedangkan data yang berupa saran dan alasan memilih jawaban dianalisis menggunakan teknik analisis kualitatif.

Dalam pengolahan data, persentase diperoleh dengan rumus dari Sukirman, dkk. (2003:879), yaitu:

Keterangan:

$\begin{array}{ll}\mathrm{P} & \text { : frekuensi relatif /angka persentase } \\ \mathrm{f} & \text { : frekuensi yang sedang dicari persentasenya } \\ \mathrm{N} & : \text { jumlah seluruh data } \\ 100 & : \text { konstanta }\end{array}$


Tabel 1. Klasifikasi Prosentase

\begin{tabular}{lll}
\hline Prosentase & Klasifikasi & Makna \\
\hline $\mathbf{0 - 2 0 \%}$ & Tidak baik & Dibuang \\
$\mathbf{2 0 , 1 - 4 0 \%}$ & Kurang baik & Diperbaiki \\
$\mathbf{4 0 , 1 - 7 0 \%}$ & Cukup baik & Digunakan(bersyarat) \\
$\mathbf{7 0 , 1 - 9 0 \%}$ & Baik & Digunakan \\
$\mathbf{9 0 , 1 - 1 0 0 \%}$ & Sangat baik & Digunakan \\
\hline
\end{tabular}

Guilford (dalam Alvian Nor-Achmad.2014:41)

\section{Hasil Penelitian dan Pembahasan}

\section{Validasi Draf Produk Awal}

Produk awal pengembangan model permainan Colourfull Ball Target dalam pembelajaran permainan bola kecil pada siswa Tunarungu SDLB N di Kabupaten Kudus ) sebelum di uji cobakan dalam uji kelompok kecil, produk yang dihasilkan perlu untuk dilakukan validasi oleh para ahli yang sesuai dengan bidang penelitian ini.

Validasi dilakukan dengan cara memberikan draf produk awal model permainan Colourfull Ball Target, dengan disertai lembar evaluasi untuk ahli penjas adaptif dan ahli penjasorkes dari guru penjas Sekolah Dasar Luar Biasa (SDLB). Lembar evaluasi berupa kuesioner yang berisi aspekkualitas model permainan, saran, serta komentar dari ahli penjas adaptif dan ahli penjasorkes dari guru penjas Sekolah Dasar Luar Biasa (SDLB) terhadap model permainan Colourfull Ball Target. Hasil evaluasi berupanilai dari aspek kualitas model pembelajaran dengan menggunakan skala likert 1 sampai 5, caranya dengan mencontreng salah satu angka yang terdapat pada lembar evaluasi tersebut.

Hasil rekapitulasi evaluasi ahli untuk kualitas model permainan Colourfull Ball Target dapat diamati pada tabel 2 berikut :

\begin{tabular}{lll}
\hline No & Ahli & Prosentase \\
\hline $\mathbf{1}$ & Ahli Penjas adaptif & $72,0 \%$ \\
$\mathbf{2}$ & Ahli Penjasorkes & $74,66 \%$ \\
\hline & Rata-rata & $73,33 \%$ \\
\hline
\end{tabular}

Sumber: Data Peneliti

Sehingga dapat disimpulkan bahwa pengembangan permainan Colourfull Ball Target dalam

pembelajaran permainan bola kecil sebelum uji coba skala kecil sudah masuk dalam kategori

penilaian "baik".

Berdasarkan masukan dari ahli. Dari produk awal yang sudah dibuat mendapat saran dari ahli yaitu tentang jarak lari dari mengambil amplop sampai dikotak bola yang disesuaikan dengan kemampuan siswa. Yang semula 7 (tujuh) meter menjadi 5 (lima) meter karena terlalu jauh. Selain itu bola yang semula ada tulisan warna bola diganti dengan gambar warna bola saja supaya tidak menyulitkan siswa karena tidak semua anak bisa membaca dengan lancar.

Uji coba Skala Kecil

Berdasarkan hasik kuesioner yang dilakukan oleh ahli pada uji coba skala kecil diperoleh hasil sebagai berikut:

\begin{tabular}{lll}
\hline No & Ahli & Prosentase \\
\hline $\mathbf{1}$ & Ahli Penjas adaptif & $81,33 \%$ \\
$\mathbf{2}$ & Ahli Penjasorkes & $85,33 \%$ \\
\hline & Rata-rata & $83,33 \%$ \\
\hline
\end{tabular}

Sumber: Data Peneliti

Berdasarkan data diatas, dapat dilihat bahwa hasil total dari semua aspek oleh ahli penjas adaptif dan ahli penjasorkes, dengan ratarata presentase $83,33 \%$. Dari hasil presentase rata-raa tersebut maka termasuk kategori baik.

Sedangkan untuk hasil penilaian siswa yang terdiri dari 3aspek yaitu aspek kognitif, afektif, dan psikomotor adalah sebagai berikut: untuk aspek kognitif sebesar 70\% kategori "Baik", untuk afektif sebasar $85 \%$ kategori "Baik", dan untuk aspek psikomotor sebesar $82 \%$ kategori "Baik". Sehingga model permainan Colourfull Ball Target ini baik digunakan dalam pembelajaran penjasorkes.

Berdasarkan saran dari ahli penjas adaptif dan ahli penjasorkes pada produk atau model yang

telah diujicobakan ke dalam uji skala kecil, maka dapat segera dilaksanakan revisi produk. Proses revisi produk berdasarkan saran ahli penjas adaptif dan ahli penjasorkes terhadap kendala dan permasalahan yang muncul setelah uji coba skala kecil. Proses revisi adalah sebagai berikut :

1) Jarak dari tempat kotak amplop dengan kotak bola diberi rintangan , seperti lari zig-zag untuk menambah rintangan.

2) Pada pos terakhir yaitu menangkap bola diganti dengan keranjang agar mempermudah siswa untuk melempar maupun menangkap bola.

3) Tempat hinggap diperjelas warnanya, serta tempat batas untuk menangkap bola diperjelas warnanya.

\section{Uji Coba Lapangan/ Skala Besar}

Berdasarkan hasik kuesioner yang dilakukan oleh ahli pada uji coba lapangan diperoleh hasil sebagai berikut:

\begin{tabular}{lll}
\hline No & Ahli & Prosentase \\
\hline $\mathbf{1}$ & Ahli Penjas adaptif & $80,00 \%$ \\
$\mathbf{2}$ & Ahli Penjasorkes & $89,33 \%$ \\
$\mathbf{3 .}$ & Ahli Penjasorkes & $82,00 \%$ \\
\hline & Rata-rata & $89,73 \%$ \\
\hline
\end{tabular}

\section{Sumber: Data Peneliti}

Berdasarkan data diatas, dapat dilihat bahwa hasil total dari semua aspek oleh ahli penjas adaptif dan ahli penjasorkes, dengan ratarata presentase $89,73 \%$. Dari hasil presentase rata-raa tersebut maka termasuk kategori baik.

Sedangkan untuk hasil penilaian siswa yang terdiri dari 3 aspek yaitu aspek kognitif, afektif, dan psikomotor adalah sebagai berikut: untuk aspek kognitif sebesar 75,5\% kategori "Baik", untuk afektif sebasar 88,5\% kategori "Baik", dan untuk aspek psikomotor sebesar 78,5\% kategori "Baik". Sehingga model permainan Colourfull Ball Target ini baik digunakan dalam pembelajaran penjasorkes.

\section{HASIL AKHIR}

Hasil akhir dari penelitian pengembangan ini adalah produk model pembelajaran permainan Colourfull Ball Target yang berdasarkan pada data uji coba I $(\mathrm{N}=10)$ dan data uji coba II $(\mathrm{N}=20)$.

Dari hasil pengembangan permainan yang dikembangkan sesuai dengn prosedur pengembangan, maka didapatkan sebuah produk yang sesuai dengan karakteristik siswa Sekolah Dasar Luar Biasa adalah permainan "Colourfull Ball Target". Hal ini terbukti dari hasil analisis data uji coba didapatkan presentase jawaban iatu uji coba I 83,33\%(Baik) dan hasil uji coba lapangan $89,78 \%$ (Baik), hasil dari penilaian pada aspek kognitif, afektif dan psikomotor uji coba I dan uji coba lapangan hasil rata-ratanya baik. Berdasarkan kriteria yang telah ditentukan maka permainan Colourfull Ball Target ini telah memenuhi kriteria baik, sehingga dari uji lapangan model ini dapat digunakan untuk siswa SDLB Negeri di Kabupaten Kudus.

Hasil penilaian dari guru, maka diambil kesimpulan bahwa permainan Colourfull Ball Target dapat digunakan sebagai sarana pendukung dalam pembelajaran permainan bola kecil dengan hasil penilaian dari aspek kognitif, afektif dan psikomotor dengan rata-rata dari uji coba I dan dari uji coba II hasilnya baik. 


\section{Simpulan dan Rekomendasi}

Berdasarkan hasil penelitian telh dilakukan, maka disimpulkan bahwa model permainan Colourfull Ball Target ini dapat diterapkan untuk siswa tunarungu SDLB N diKabupaten Kudus. Dapat disarankan bagi guru penjasorkes SDLB N di Kabupaten Kudua agar model permainan ini menjadi alternatif penyampaian pembelajaran permainan bola kecil agar pembelajaran lebih variatif dan menarik.

\section{REFERENCES}

Ali, Muhammad. Guru dalam Proses Belajar Mengajar. Jakarta: Sinar Baru Algensido.

Biro Humas dan Hukum Kementerian Negara Pemuda dan Olahraga Republik Indonesia. 2008. Undang-undang Republik Indonesia Nomor 3 Tahun 2005 Tentang Sistem Keolahragaan Nasional.

Elly Sari Melinda. 2013. Pembelajaran Adaptif Bagi Anak Berkebutuhan Khusus. Jakarta Timur : Luxima

Esthy Wikasanti. 2014. Pengembangan Live Skill untuk Anak Berkebutuhan Khusus. Jogjakarta: Redaksi Nasional.

Gino, H.J. et al. 2000. Belajar dan Pembelajaran I. Surakarta:UNS Perss.

Hustarta dan Yudha M. Saputra. 2000. Belajar dan Pembelajaran. Jakarta: Departement Pendidikan Nasional.

IG.A.K Wardani., dkk. 2011. Pengantar Pendidikan Luar Biasa. Jakarta : Universitas Terbuka

Jawandono, Irawan. 2014. Pengembangan Model Pembelajaran Penjas Adaptif Melalui Media Permainan Bangun Pintar Berwarna
Pada Siswa Tunarungu SDLB Negeri Semarang. Skripsi. Program Sarjana Universitas Negeri Semarang.

Rahayu, Ega Trisna.2013. Strategi Pembelajaran Pendidikan Jasmani. Bandung: Alfabeta

Samsudin. 2008. Pembelajaran Pendidikan Jasmani Olahraga dan Kesehatan SD/MI. Jakarta: Pranada Media Grup.

Slameto. 2003. Belajar dan Faktor-faktor yang Menpengaruhinya. Jakarta: Rineka Cipta.

Subagiyo. 2008. Perencanaan Pendidikan Jasmani Dan Kesehatan. Jakarta: Universitas Terbuka.

Sugiono. 2009. Penelitian Kualitatif Kuantitatif dan RnD. Bandung: Alfabeta.

Sukintaka.2004. Teori Pembelajaran. Bandung: Yayasan Nuansa Cendekia.

Suwarjo dan Imania E.2010.Permainan (Games) dalam Bimbingan dan Konseling.Yogyakarta:Paramitra Publishing.

Tarigan Beltasar. 2000. Pendidikan Jasmani Adaptif. Departemen Pendidikan Nasional Dasar dan Menengah. Jakarta.

Tim Pengembang Bahan Ajar Program Khusus SLB Tunarungu. 2010. Bina Komunikasi Persepsi Bunyi dan Irama. Jakarta : Kementerian Pendidikan Nasional Badan Penelitian dan Pengembangan Pusat Kurikulum.

Wina Sanjaya. 2011. Strategi Pembelajaran Berorientasi Standar Proses Pendidikan. Jakarta: Kencana.

Yani Meimulyani dan Asep Tiswara. 2013. Pendidikan Jasmani Adaptif Bagi Anak Berkebutuhan Khusus. Jakarta Timur : Luxima. 